\title{
CALENDAR OF COMPUTER-CHESS EVENTS
}

For the benefit of readers wishing to enter programs in computer-chess competitions or to attend a tournament or conference, we list future events. Organizers are invited to send full details to the Editor for inclusion in the calendar.

\section{3}

\section{February 14-17}

The $23^{\text {rd }}$ ACM International Computer-Chess Championship, to be held in Indianapolis, Indiana.

Details: Monty Newborn, School of Computer Science, 3480 University Street, McGill University, Montreal, Quebec, Canada, H3A 2A7. Tel.: 514-398-7079. [See also pages 243-245 of this issue.]

\section{May 5-7, 10-12}

The 1993 AEGON Man-Computer Tournament, to be held in The Hague, The Netherlands.

Details: Cock de Gorter, Valkenboskade 607, 2563 JE The Hague, The Netherlands.

\section{July 1-2}

The Advances in Computer Chess 7 conference, to be held in Maastricht, The Netherlands.

Details: Jaap van den Herik, Department of Computer Science, University of Limburg, P.O. Box 616, 6200 MD Maastricht, The Netherlands. [See also page 174 of the September 1992 issue of this Journal.]

\section{August 2-6}

Uniform Platform Computer-Chess Tournament, to be held in London, UK.

Details: Don Beal, Department of Computer Science, Queen Mary and Westfield College, Mile End Road, London E1 4NS, UK. [See also pages 173-174 of the September 1992 issue of this Journal.]

\section{August 15-28}

The $1^{\text {st }}$ Mind Sports Olympiad, including the $5^{\text {th }}$ Computer Olympiad. To be held in London, UK.

Details: David Levy, 89, Constantine Road, London NW3 2LP, UK.

\section{THE $23^{\text {rd }}$ ACM INTERNATIONAL COMPUTER-CHESS CHAMPIONSHIP}

February 14-17, 1993, Indianapolis, Indiana

The ACM's 1993 Computer Science Conference will host the $23^{\text {rd }}$ ACM International Computer-Chess Championship. The championship will be a five-round Swiss-style event with two rounds on Sunday, February $14^{\text {th }}$, one on Monday, February $15^{\text {th }}$, one on Tuesday, February $16^{\text {th }}$, and the final round on Wednesday, February $17^{\text {th }}$. A total of $\$ 8,000$ in prizes will be awarded to the authors of the top three finishers and to the best small computing system. The event will be held in the Indianapolis Hyatt Hotel.

The $22^{\text {th }}$ ACM International Computer-Chess Championship was won by Deep Thought, programmed by Fenghsiung Hsu and Murray Campbell. M_Chess finished second and Cray Blitz was third. Deep Thought passed up the recent World Computer-Chess Championship, held in Spain in November, 1992, giving up their title to Chessmachine, programmed by Ed Schröder. It is hoped that these teams will compete in Indianapolis.

In addition to the tournament, a special program for students in the Indianapolis area will be held during the afternoon of Saturday, February $13^{\text {th }}$ and on the morning of Sunday, February $14^{\text {th }}$. The students will first compete among themselves for the right to play the computers on Sunday morning, the best players will take on the machines.

Mike Valvo will serve as Tournament Director. He is one of America's top blindfold chess-players. Danny Kopec will serve as Assistant Tournament Director. Ken Thompson will head the Entries Committee.

For more information or to apply, please write or call: Monty Newborn, School of Computer Science, 3480 University Street, McGill University, Montreal, Quebec, Canada, H3A 2A7 (Tel.: 514-398-7079). 


\section{The $23^{\text {rd }}$ ACM International Computer-Chess Championship}

Indianapolis, Indiana

February 14-17, 1993

\section{Entry Form}

Name(s) of programming team:

Name and address for correspondence:

Affiliation (optional):

Work Telephone:

Home Telephone:

**********************************************************************************************

Name of Program:

Language:

Rating: Basis of rating:

Language of program:

Nodes per second:

Individual (and his/her address and telephone) who can recommend program (if the program has not participated in major tournaments):

Computer that will be used:

Location of computer:

Mips: Memory size: Word size:

Space required by program: Hash table(s)? If yes, how big:

Multiprocessor? If yes, how many processors: Special-purpose circuitry?

Other:

You must bring your own terminal!!!!!! Will you need a telephone line? $(\mathrm{Y} / \mathrm{N})$

Who will be in Indianapolis to serve as operator of your program?

Signature: Date:

Please return this form to: Ken Thompson, Room 2C 519, Bell Labs, Murray Hill, NJ 07974, USA. 
As part of the $23^{\text {rd }}$ ACM Computer-Chess Championship a panel discussion will be held on Tuesday, February $16^{\text {th }}, 1993$ from 3:30-5:00 p.m. in the Hyatt Hotel, under the title Computer Chess: What Remains? Panelists:

- Professor T.A. Marsland (chair) is from the University of Alberta, Edmonton, Canada. He is a longstanding member of the computer-chess community and has written extensively on tree-searching methods.

- Dr. R. Hyatt is at the University of Alabama, Birmingham. He has worked for many years developing the supercomputer version of the Cray Blitz chess program, which was Computer World Champion 19831989.

- Dr. R. Levinson is at the University of California at Santa Cruz. He is principal investigator in the "Morph" learning project.

- Professor M. Newborn is at McGill University, Montreal, Canada. He too is an established member of the computer-chess community. Developer of the first working parallel chess program, and active organizer of North American computer-chess events.

- J. Stanback is at HP Labs in Fort Cóllins. He is author of the highly successful ZARKOV chess program for small computers.

Further it is intended that either Murray Campbell or "CB" Hsu also hope to be able to serve as a panelist.

- Dr. F-h Hsu and Dr. M. Campbell are both at IBM Yorktown Heights. They are the main components in the design and testing of Deep Thought, the 1989-1992 Computer World Champion Chess Program currently undergoing major hardware revision.

\section{Theme}

The panelists will review the state of computer chess as the best programs begin to match world champion standards. Although it is difficult to judge when programs will be superior (estimates range from 5 to 25 years), there is a sense of inevitability. This raises several questions like: What else has been accomplished by this work? What were the spin-offs for Artificial Intelligence? What other applications have benefited from the new searching methods, and data structures? And also questions like: What remains to be done? What could be done better? How to approach related domains like GO, which are less amenable to existing search techniques? This is an opportunity forr the audience to come primed with their favorite questions and to elicit expert responses from the panelists.

\section{IBM DEEP BLUE}

\section{The Editorial Board}

In the December 1992 issue of the Danish national chess magazine Skakbladet, it was announced that "IBM Deep Blue" will be presented to the world in Copenhagen, Denmark, on February 24-27, 1993. Moreover, it was stated that a four-games match between IBM Deep Blue and IGM Bent Larsen was scheduled, with playing times from 11 am to $5 \mathrm{pm}$.

From the IBM research team, Dr. Feng-hsiung Hsu gave the following comment on this announcement:

"The machine playing is not really the final Deep Blue, but Deep Thought II running the Deep Blue preliminary software/search algorithms. There are three stages of development for Deep Blue: the software simulation on DT II (Deep Blue Simulation), the preliminary version on a prototype 10-processor machine (Baby Deep Blue), and the final 1024-processor machine (Deep Blue). Only the first-stage machine will be ready for the match. The main difference between Deep Blue Simulation and DT 2 is the introduction of new search-extensions algorithms. The Deep Blue technical presentation itself will be mainly on the new Deep Blue custom VLSI single-chip chess machine.

As for the match itself, I am not sure whether it is a 3-game or a 4-game match. The machine is supposed to play against Swedish GM Andersson or Cramling on alternate days as well." 